Max-Planck-Institut für demografische Forschung

Max Planck Institute for Demographic Research

Konrad-Zuse-Strasse $1 \cdot$ D-18057 Rostock · GERMANY

Tel +49 (0) 3812081 - 0; Fax +49 (0) 3812081 - 202;

http://www.demogr.mpg.de

MPIDR WORKING PAPER WP 2008-014

MARCH 2008

\title{
Regularities and Deviations in \\ Mortality Trends of the Developed World
}

Elisabetta Barbi (ebarbi@unime.it)

This working paper has been approved for release by: James W. Vaupel (jwv@demogr.mpg.de) Head of the Laboratory of Survival and Longevity.

(C) Copyright is held by the authors.

Working papers of the Max Planck Institute for Demographic Research receive only limited review. Views or opinions expressed in working papers are attributable to the authors and do not necessarily reflect those of the Institute. 


\title{
Regularities and Deviations in Mortality Trends of the Developed World ${ }^{1}$
}

\author{
Elisabetta Barbi ${ }^{2}$
}

\begin{abstract}
By the second half of the $20^{\text {th }}$ century, mortality patterns in industrialized countries showed a continuous tendency of reduction at all ages, even at the oldest ones. However, the pace of mortality decline considerably varies depending on the country. Furthermore, in a few cases, stagnation and even an unexpected reversed pattern have been observed in more recent years. In this paper a comparative analysis of mortality trends in several developed countries is performed. The aim of the paper is to locate deviations from expected mortality patterns, and to understand the reasons for these deviations. As a first step of the analysis, a new two-dimensional relational model is applied to mortality surfaces of the selected developed countries, between 1960 and 1999, for the age range 50-99. In the second step, mortality by cause of the countries with particular structural features is analyzed through the surfaces of leading causes of death.
\end{abstract}

\section{Introduction}

By the second half of the $20^{\text {th }}$ century, developed countries enjoyed a continuous reduction in mortality at all ages, even at the oldest ones (Kannisto et al. 1994). For low-mortality areas, this tendency has been quite general, and has involved both women and men, although a time lag has been often recorded between male and female mortality improvements. However, the pace of mortality decline considerably varies depending on the country (Caselli 1996; Kannisto 1994). Furthermore, in a few cases, stagnation and even an unexpected reversed pattern have been observed in more recent years (Janssen et al. 2003, 2004; Vallin and Mesle 2004).

\footnotetext{
${ }^{1}$ An earlier version of this paper has been presented at the XXV IUSSP International Population Conference, Tours, France, July 18-23, 2005

${ }^{2}$ Department of Economics, Statistics, Mathematics and Sociology "W. Pareto”, University of Messina, Italy. Email: ebarbi@unime.it
} 
In this paper a comparative analysis of mortality trends in several developed countries is performed. The aim of the paper is to locate deviations from expected mortality patterns, and to determine the reasons for these deviations. As a first step of the analysis, a new twodimensional relational model is applied to surfaces of mortality rates by age and time of the selected countries to extract and compare structural information like age and time patterns, and speed of changes of the different populations. In the second step, mortality by cause of the countries with particular structural features is analyzed through the surfaces of the leading causes of death (Barbi et al. 2004).

\section{Data and Methods}

The analyses presented here focus on adult and old age mortality (aged 50-99), between 1960 and 1999 in low-mortality countries included in the Human Mortality Database (www.mortality.org). Probabilities of dying for single years of age and single calendar years are obtained from this data collection.

Regarding cause specific mortality data, probabilities of dying by groups of causes and by five-years age groups are estimated from data available in the World Health Organisation Mortality Database (www.who.int/whosis).

All-cause mortality surfaces are analyzed by means of a new relational model. Relational models of mortality are based on a standard mortality schedule capturing the complexity of age patterns of mortality, and on parameters capturing deviations from the standard (Brass 1971; Himes et al. 1994). This concept can be generalized so that the standard mortality schedule is defined over time as well as age (Camarda et al., 2005). If $\mu_{0}(x, y)$ is a (given) standard force of mortality at age $x$ and time $y$ (i.e. a standard mortality surface) then, following the specification of models developed by Lee Carter (1992) and Vaupel (1999), the correspondent force of mortality $\mu(x, y)$ for a generic country may be estimated by the following relational model:

$$
\mu(x, y)=\mu_{0}(x, y) \exp [k(y) r(x)]
$$

where $k(y)$ is a function of time capturing deviations from the standard over time and $r(x)$ is a function of age describing the relative impact of these deviations at different ages. These two functions may be estimated by the maximum likelihood method, using the binomial distribution 


$$
L=\sum_{x} \sum_{y} D(x, y) \ln q(x, y)+[N(x, y)-D(x, y)] \ln (1-q(x, y)),
$$

where $D(x, y)$ and $N(x, y)$ are respectively death counts and population counts (the population exposed to the risk of death) at age $x$ and time $t$, and $q(x, y)$ is the probability of dying at age $x$ and time $y$.

The choice of a standard represents a critical issue in the specification of the model. Different choices of the two-dimensional standard mortality schedule are possible but alternative standards lead obviously to different interpretations of the model and to different results. A conventionally-adopted standard is, for example, the average mortality surface for a number of populations for different countries. Here, the standard surface has been computed following the concept of "best practice" used by Oeppen and Vaupel (2002) to evaluate the life expectancy increase in the record-holding country from 1840 to the present. This idea has been used here to estimate the best-practice survival - or, in other words, the lowest mortality - by age and time. Figure 1 shows male and female surfaces of the lowest probabilities of dying (i.e. the best-practice mortality surfaces), between 1960 and 1999, from birth to age 99, computed accounting for the probabilities of dying of 13 low-mortality countries: Austria, Denmark, Finland, France, West Germany, Italy, Japan, Netherlands, Norway, Spain, Sweden, Switzerland, USA.

Cause-specific mortality profiles are analyzed exploiting a simple but powerful tool: the surface of the leading causes of death, representing the highest cause-specific probability of dying at a given age and time. After locating the predominant cause of death (or the predominant location in a group of diseases) over age and time, is then possible to focus on this specific cause (or location) for a more in-depth investigation.

\section{Application}

Figure 2 depicts the evolution of life expectancy at ages 60 and 80, between 1960 and 2002, in 13 low-mortality countries. Roughly speaking, deviations from expected patterns are more evident for women than for men. For women, unfavourable trends started in the early eighties in Denmark, U.S., Norway, The Netherlands and, to a certain extent, in Finland. These negative deviations are still very remarkable at older ages especially when compared with very favourable trends of the Japanese women. For men, as said, the picture is more homogeneous, although the positive tendency for Japan and, at older ages, a period of stagnation for Denmark and The Netherlands are appreciable. In particular, at the beginning 
of the sixties, the United States show one of the highest life expectancy at age 60 for women, and at age 80 for both women and men whereas Japan finds itself at a disadvantage. However, Japan has caught up at a remarkable pace at all ages and today is the country with the highest life expectancy in the world.

A more detailed analysis of deviations from expected mortality patterns by single year of age and single calendar year is possible by applying the two-dimensional relational model described in section 2. The model has been applied to mortality data of four countries characterized by a particular mortality pattern: Denmark which shows one of the most unfavorable trends for both the sexes; Japan which, on the contrary, experiences the most positive pattern; Spain because of its apparent regularities in mortality trends; and U.S. which, after being the country with the highest life expectancy at old ages, is experiencing, for women only, a period of stagnation.

Figure 3 shows the estimated functions $k(y)$ and $r(x)$ of the relational model fitted to male and female probabilities of dying of the chosen countries, between 1960 and 1999, from age 50 to 99 . The fit of the model to the data (not shown) is generally quite good, with exceptions after age 85 at the beginning of the study period for Danish women, and in the last years for Japanese men. By the mid seventies Denmark and Japan show remarkable diverging trends and different age patterns of deviation from the standard for both sexes. While in Japan the deviation is reducing over time and its relative impact is higher at older ages, in Denmark this is increasing fast for both males and females, with a greater importance at adult and young-old ages especially for women. Age and time patterns of deviations from the standard for U.S. women are very similar to those estimated for Denmark. For men, after a slight reduction, by the mid seventies, the deviation from the standard stays constant and, as for women, the impact is higher at adult and young-old ages. Spain too shows a constant deviation for both women and men but its relative impact is increasing with age especially for women. 

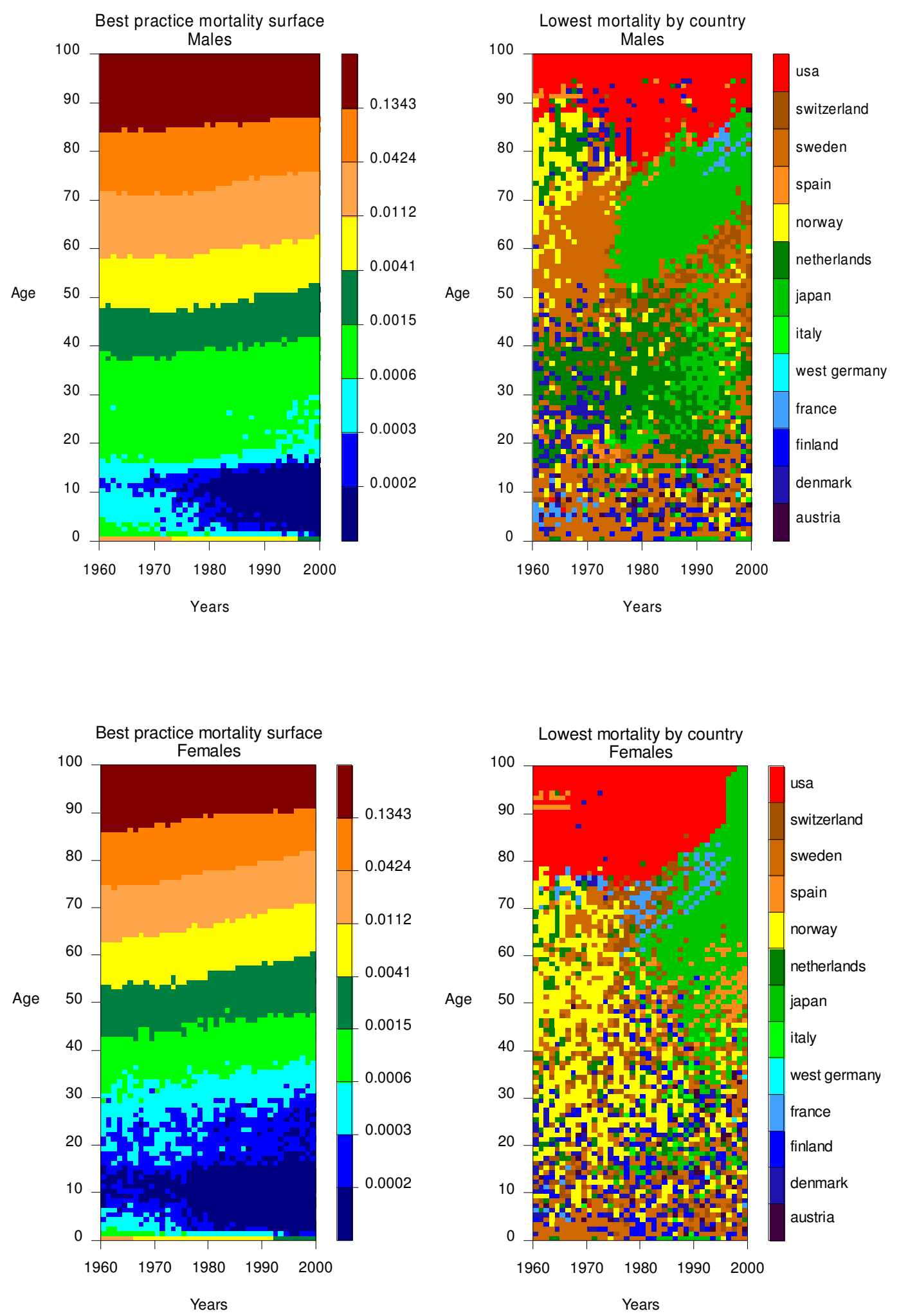

Figure 1. Best-practice mortality surface according to probabilities of dying of 13 lowmortality countries: Austria, Denmark, Finland, France, West Germany, Italy, Japan, Netherlands, Norway, Spain, Sweden, Switzerland, USA. 1960-1999. 

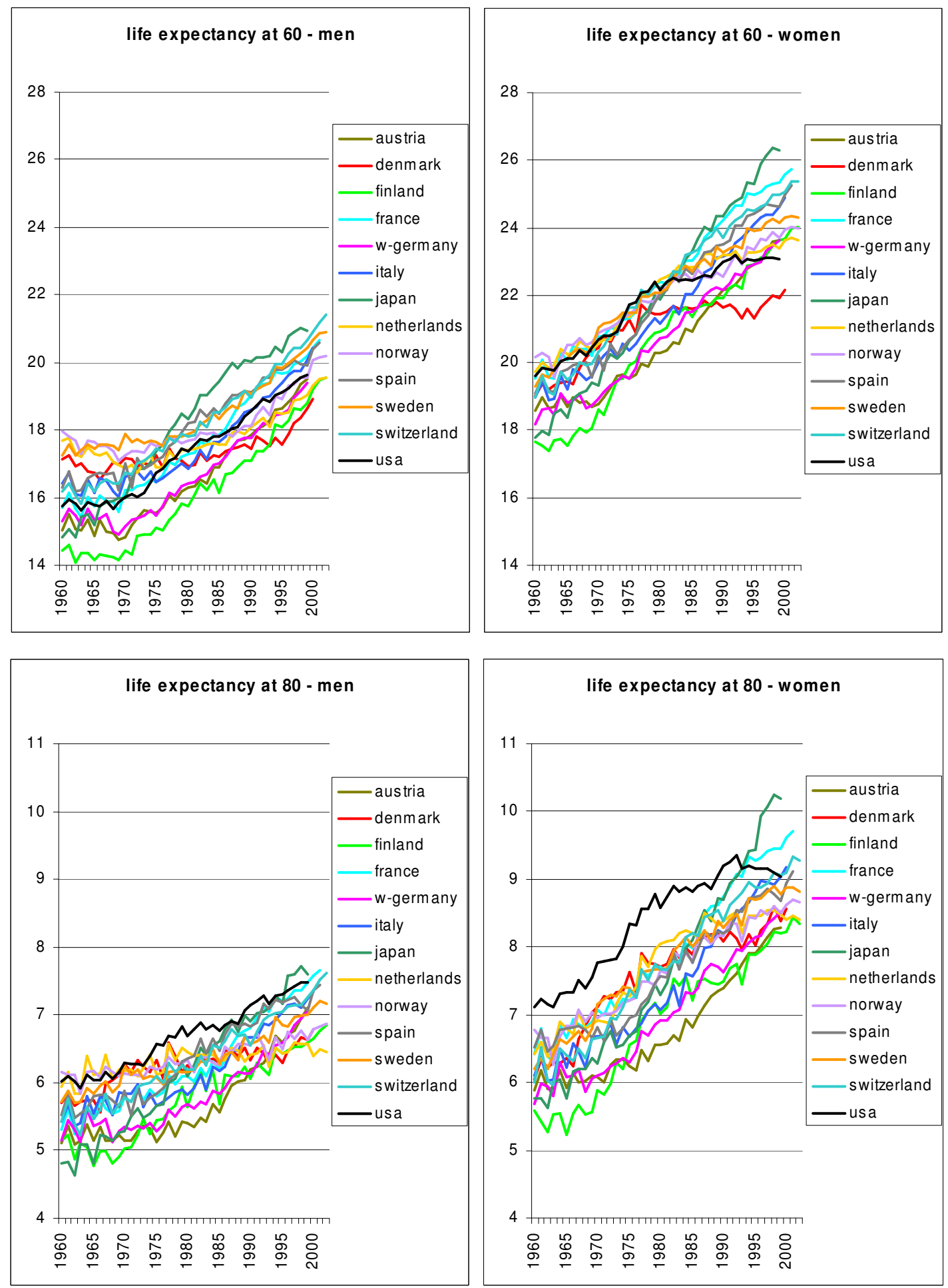

Figure 2. Life expectancy at ages 60 and 80 in 13 low-mortality countries from 1960 to 2002. 

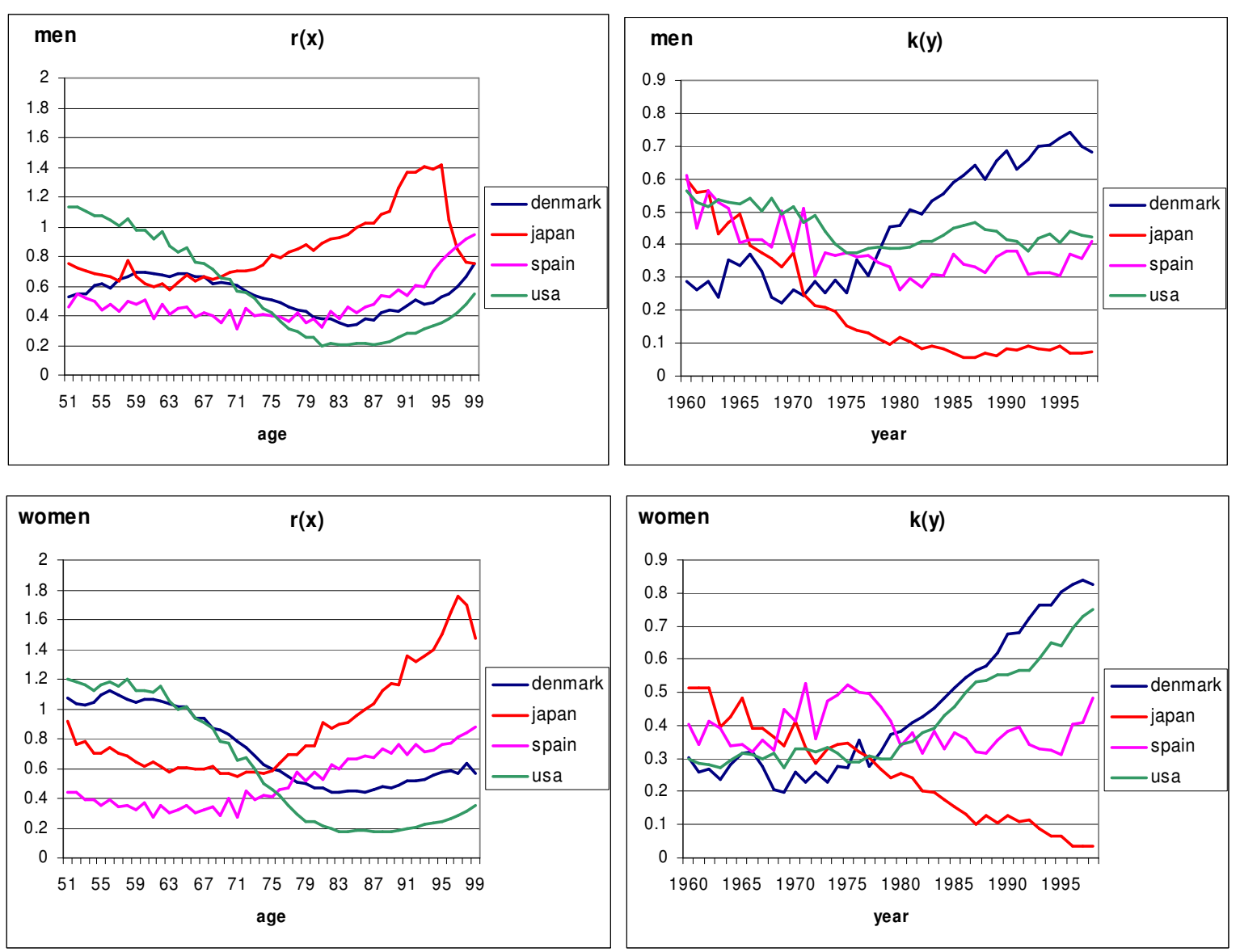

Figure 3. Estimated age and time functions, $r(x)$ and $k(y)$, of the relational model.

Let's turn now to cause-specific mortality. The analysis here has been limited to Japanese and U.S. female mortality from the group of diseases of the circulatory system, which has been classified into four locations: ischaemic heart diseases, other heart diseases, cerebrovascular diseases and other diseases of the circulatory system. ${ }^{3}$ Figure 4 shows the leading locations by age and time of this group of causes in the two countries. In Japan, cerebrovascular diseases are the first category at all ages considered until 1986 when, at older ages, the leading location becomes "other hearth diseases". In the U.S., ischaemic hearth diseases are the most important category at all ages for the entire study period.

\footnotetext{
${ }^{3}$ According to the $9^{\text {th }}$ Revision of the International Disease Classification: ischaemic heart disease: $410-414$; other heart diseases: 390-398, 401-405, 415-429; cerebrovascular diseases: 430-438; other diseases of the circulatory system: 440-459.
} 

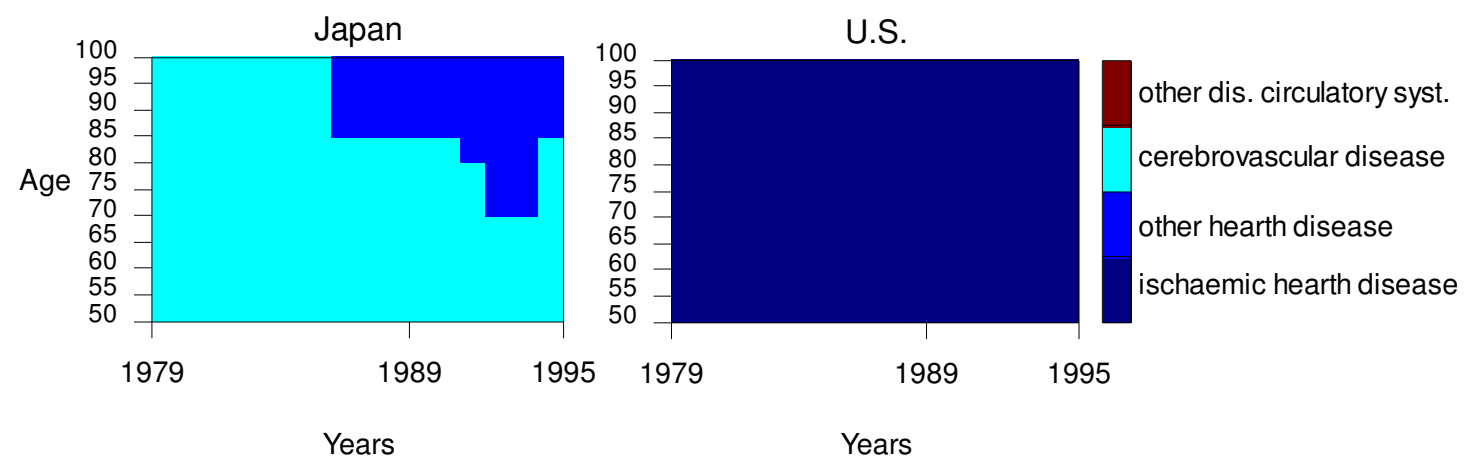

Figure 4. Leading location by age and time among diseases of the circulatory system.
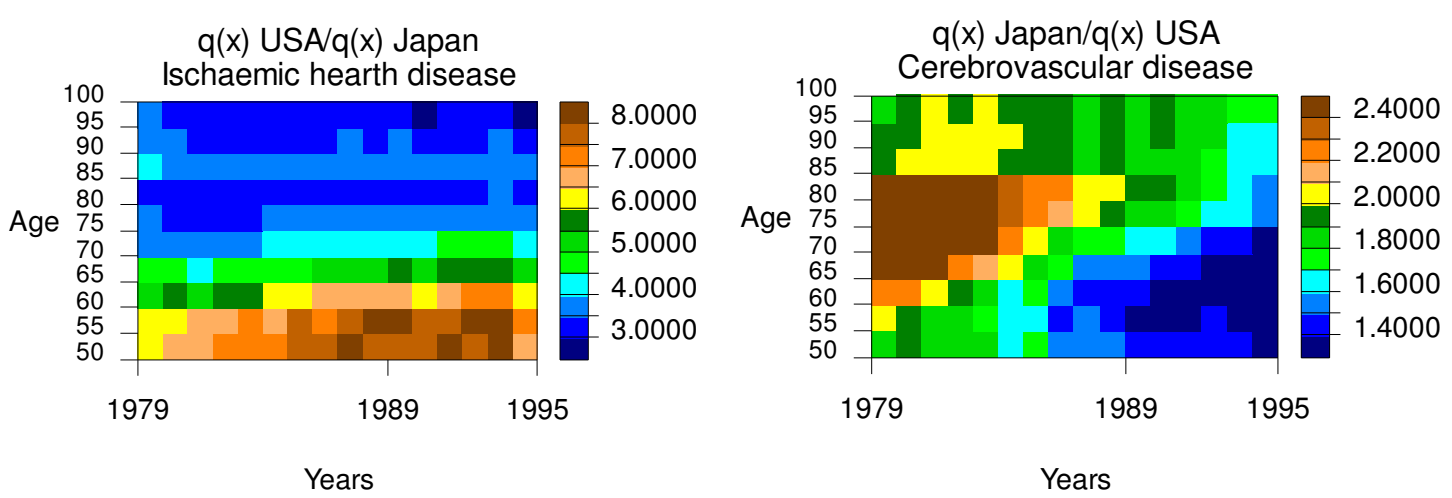

Figure 5. Ratios of Japanese and U.S. probabilities of dying from ischaemic hearth disease and cerebrovascular disease.

Focusing now on these two country-specific predominant locations, cerebrovascular diseases and ischaemic hearth diseases, the analysis reveals completely different age and time patterns (Figure 5). Probabilities of dying from cerebrovascular diseases of the two countries tend to converge over time, due to a faster decline in Japan, thus reducing the Japan disadvantage in mortality from cerebrovascular diseases. On the contrary, the high difference between probabilities from ischaemic hearth diseases of the two countries stays constant and even slightly increases during the last years of observation, thus maintaining the US disadvantage in mortality from ischaemic hearth diseases. The highest discrepancy between U.S. and Japanese probabilities of dying from ischaemic hearth diseases is recorded at adult and young-old ages. Although different classifications of causes of death in the two countries may affect results to some extent, these findings perfectly match with 
the age and time patterns of deviation from the "optimal position" estimated by the relational model for U.S. and Japanese women, helping understand possible reasons for these deviations .

Here the analysis involved only two countries and focused only on one group of causes of death. This study will be extended to other countries of interest and to all causes of death grouped in main categories. The resulting detailed picture may prove useful to disentangle and explain unexpected mortality patterns.

\section{Acknowledgements}

This paper was made while I was a guest researcher at the Max Planck Institute for Demographic Research in Rostock, Germany. I gratefully acknowledge the support of Prof. James Vaupel at the Max Planck Institute in Germany.

\section{References}

Barbi E., Caselli G., Yashin A. (2004), Age and time patterns of mortality by cause in Italy: A mortality surface approach, Proceedings of the XLII Scientific Meeting of the Italian Society of Statistics, Bari 9-11 June, 2004.

Brass W. (1971), On the scale of mortality. In Brass W. (ed.), Biological Aspects of Demography, Taylor \& Francis, London.

Camarda C.G., Barbi E., Gampe J., Vaupel J.W. (2005), Mortality Dynamics and Policy Changes: The Case of Germany, Poster presented at XXV IUSSP International Population Conference, Tours, France, July 18-23, 2005.

Caselli G. (1996), Future longevity among the elderly. In Caselli G. and Lopez A. (eds.), Health and mortality among elderly populations, Oxford: Clarendon Press.

Himes C.L., Preston S. H., Condran G.A. (1994), A Relational Model of Mortality at Older Ages in Low Mortality Countries, Population Studies, Vol. 48, No. 2, 269-291.

Janssen F. et al. (1993), Stagnation in mortality decline among elders in The Netherlands, The Gerontologist, 43(5), 722-734.

Janssen F., Mackenbach J.P., Kunst A.E. (2004), Trends in old-age mortality in seven European countries, 1950-1999, Journal of Clinical Epidemiology, 57, 203-216.

Kannisto V. (1994), Development of oldest-old mortality, 1950-1990: Evidence from 28 developed countries. Odense University Press.

Kannisto V., Lauritsen J., Thatcher A.R., Vaupel J.W. (1994), Reductions in mortality at advanced ages: several decades of evidence from 27 countries. Population and Development Review, 20(4), 793-810.

Lee R.D. and L.R. Carter (1992), Modeling and forecasting U.S. Mortality. Journal of the American Statistical Association. Vol 87, No. 419, 659-671. 
Oeppen J., Vaupel J.W. (2002), Broken limits to life expectancy, Science, 30.

Vallin J., Meslé F. (2004), Convergences and divergences in mortality. A new approach to health transition, Demographic Research, special collection 2.

Vaupel J.W. (1999), The long-term pattern of adult mortality and the highest attained age. Discussion on the paper by A.R Thatcher. Journal of the Royal Statistical Society Series A: Statistics in Society. 162: 31-32. 